\title{
Signos, comunicação e mundo da vida: a abordagem sócio-fenomenológica da semiótica de Alfred Schütz
}

$\frac{\text { MiCHAEL HANKE }}{\text { Universidade Federal de Minas Gerais /UFMG }}$ 


\section{Resumo}

Através da análise da relação entre o indivíduo e a sociedade, Alfred Schütz, em sua abordagem socio-fenomenológica, percebeu a importância da relação entre comunicação e processos semióticos desenvolvendo uma teoria semiótica. Representação, essencial para a noção de signos em Schütz, assim entendida como uma relação entre significante e significado, é por sua vez introduzida pelo usuário em um ato de interpretação construtiva. O conceito de "apresentação" desenvolvido subseqüentemente engloba o sentido objetivo no nivel de: a) um sistema de signos; b) interpretação subjetiva; c) situação ou contexto; $e$, levando em consideração a função comunicativa do processo de signos, d) um produtor de signos e seu complemento e e) um receptor de signos.

\section{Palavras-chave}

teoria de signos, representação, apresentação, socio-fenomenologia, comunicação e intersubjetividade

\section{Abstract}

By analyzing the relation between individual and society, Alfred Schütz in his socio-phenomenological approach perceived the importance of mediating communication and sign processes, and consequently developed a semiotic theory. Representation, understood as essential for his sign concept, is seen here as a relation between signifier and signified which is installed by the user in a constructive act of interpretation. The subsequently developed concept of "appresentation" comprises the objective meaning at the level of a) a sign system; b) subjective interpretation; c) situation or context; and, taking into account the communicative function of the sign process, d) a sign producer and its complement, e) a sign recipient.

\section{Key words}

sign theory, representation, apresentation, sociophenomenology, communication and intersubjectivity 


\section{Nota introdutória: biografia e obras}

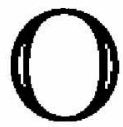

pensador austríaco Alfred Schütz desenvolveu uma teoria genuína, buscando esclarecer a relação entre sujeito e sociedade. Não estando satisfeito com as teorias vigentes em sua época (que ele critica, mas de maneira moderada), propõe uma nova abordagem (ver também Hanke 2002, 2003b, 2003c). Schütz, assim, refere-se a dois pensadores e suas teorias: Max Weber, que tem um papel significativo no início, porém muito diminuído no final; e Edmund Husserl, cuja influência nunca declina.

Nascido em Viena em 1899, Alfred Schütz, por ser de ascendência judaica, não teve a permissão de se engajar em uma carreira acadêmica. Formado em direito, ele ganhava a vida como jurista em um banco internacional. Prevendo os desenvolvimentos políticos na Europa, emigrou primeiramente para Paris em 1938 e, finalmente, para Nova Iorque, em 1939. Em Nova Iorque tornouse professor de Sociologia e Psicologia Social na pós-graduação da New School for Social Research, mas foi apenas em 1952 que ele obteve a dedicação exclusiva como docente e pôde, com isso, deixar seu trabalho no banco. Pois, até então, ele trabalhava cientificamente somente à noite e durante as férias.

Após sua chegada aos Estados Unidos, ele substitui seu idioma alemão pelo inglês. É por essa razão que um número razoável de suas obras no período dos anos 40 e 50 , recebeu publicação primeiramente em inglês (os Collected Papers I - III) e só depois foram realizadas as traduções para o alemão. É possível, portanto, um acesso a esse autor através das obras em inglês. Uma edição crítica dos Collected Papers de Schütz em alemão 
está sendo preparada e deverá, presumivelmente, ser concluída em alguns anos.

Durante sua vida, apenas um livro de Schütz foi publicado (Der sinnhafte Aufbau der sozialen Welt. Eine Einleitung in die verstehende Soziologie - A estruturação significante do mundo social. Uma introdução para a Sociologia do Entendimento). Ele trabalhou nessa obra por doze anos, pensando detalhadamente nos problemas que nunca deixaria de perseguir. As obras posteriores (em inglês) devem ser vistas como uma continuação desse ponto de partida. Entretanto, ele não conseguiu concluir sua obra final, Strukturen der Lebenswelt, em 2 volumes [Estruturas do Mundo da Vida], porque faleceu em 1959. Ambos foram completados por Thomas Luckmann (o Vol. I em 1975, o Vol. II em 1984). Esse dado é importante visto que Luckmann escreveu um livro em conjunto com Peter Berger muito conhecido e com tradução para o português (A Construção Social da Realidade. Tratado de Sociologia do Conhecimento), que às vezes é equivocadamente considerado uma introdução a Schütz. Este livro de Berger/Luckmann, publicado em 1966, que explicitamente tem suas raízes em Schütz, na verdade pretende uma solução para os problemas não resolvidos ou provenientes do próprio Schütz, usando também outras teorias.

\section{$2 \mathrm{~A}$ abordagem sócio-fenomenológica de Schütz}

Schütz é um dos poucos sociólogos que desenvolveram uma teoria semiótica que fosse integrada em seu arcabouço teórico. Suas contribuições para a teoria da comunicação e para a semiótica são partes integrantes deste arcabouço e devem ser vistas nesse contexto. Portanto, é necessário primeiramente uma caracterização da teoria de Schütz e dos problemas com que ele estava lidando.

Schütz tem sido considerado principalmente como sociólogo e filósofo, porém não como psicólogo (muito embora sua docência incluisse a psicologia social), semioticista ou teórico da comunicação. O título sócio-fenomenológico refere-se a duas fontes principais de Schütz: o sócio-refere-se à Sociologia e à noção de 
significado subjetivo desenvolvida por Max Weber, e o fenomenológico refere-se à filosofia de Edmund Husserl.

A abordagem subjetiva está programaticamente presente no título do livro Der sinnhafte Aufbau der sozialen Welt - A estruturação significante do mundo social, que também indica a direção na qual ele pensava uma solução para os problemas e à qual ele aderiu durante toda a sua obra. $A$ estruturação significante do mundo social pretende resolver a relação entre indivíduo (Individuum) e sociedade (Gesellschaft) com a seguinte estrutura de argumentação:

1. Significado subjetivo (Weber)
2. Ego, durée (Bergson, Husserl)
3. Alter ego: comunicação e signos

4. OMundo

Social e suas

estruturas

(conforme

Estruturas do

Mundo da Vida)

A estruturação significante do mundo social progride a partir do significado subjetivo desenvolvido pelo ego e pela consciência $(1,2)$ mediado pela comunicação através de signos $(3)$ e chegando à sociedade e às estruturas do mundo social (4).

$O$ problema central de Schütz é a relação entre indivíduo e sociedade. Primordial à noção de significado (Sinn) é a visão fundamental de Weber de que o significado é subjetivo é algo que o indivíduo cunha para suas ações. O significado subjetivo é crucial para a construção do mundo social pois forma a base do problema e dá direção à análise ulterior, concluída com Estruturas do Mundo da Vida. A subjetividade é complementada e aprofundada por um estilo especifico de percepção temporal; Schütz separa o tempo interior e subjetivo do tempo físico, fazendo referência a Husserl e a Bergson. Pensando no exemplo do dormir e despertar: quando dormimos, estamos separados do tempo fisico e seguimos o ritmo temporal do nosso próprio "relógio biológico"; quando despertamos, é necessário reorientar-nos para o tempo fisico, consultando um relógio comum. A subjetividade é vista como que criada para a percepção do tempo, e o título $A$ estruturação significante ... enfatiza a construção do mundo social como uma inserção de processo pelo sujeito. 
O significado [Sinn einer Erfahrung ou meaning] ... não é uma qualidade inerente a certas experiências que emerge dentro de nosso fluxo de consciência, mas o resultado de uma interpretação de alguma experiência passada considerada no Agora atual através de uma atitude reflexiva. (Schütz 1967, p.210)

Há, portanto, uma diferença com relação ao programa de Berger/Luckmann porque The Social Construction of Reality (ou $A$ construção social da realidade) expressa, como escreve Helmuth Plessner em sua introdução à edição alemã (introdução não contida na edição portuguesa), que os critérios para qualquer tipo de realidade são sociais em natureza. Berger/Luckmann elaboram uma síntese de partes de teoria retiradas de quase todas as partes da Psicologia Social, Sociologia do Conhecimento, Teoria dos Papéis e teorias gerais sobre a sociedade, para comporem uma construção social das realidades significantes, assim esse título poderia ser referente ao ponto de partida de Schütz (Grathoff 1989, p.60).

Apesar de estabelecerem focos diferentes, ambos os arcabouços concordam em que a realidade é construtiva por natureza, que é um insight que subjaz ao construtivismo contemporâneo (cf. Goodman 1978) e que Schütz formula da seguinte forma:

Todo o nosso conhecimento do mundo, tanto no senso comum quanto no pensamento cientifico, envolve construtos, i.e., um conjunto de abstrações, generalizações, formalizações, idealizações específicas ao nivel respectivo de organização do pensamento. Em sentido estrito, não existem coisas tais como os fatos puros e simples. Todos os fatos são, ab initio, selecionados de um contexto universal pelas atividades de nossas mentes. São, portanto, sempre fatos interpretados ... (Schütz 1967, p.5)

Enquanto Berger/ Luckmann enfatizam o caráter social dessa atividade construtora, para Schütz ela é subjetiva. Dessa forma a questão fundamental da sociologia do século 20 e também o ponto 
de partida para Schütz, de qual natureza seria a relação entre o indivíduo e a sociedade, é resolvida com uma ênfase diferente. Mas, deve-se manter em mente que o Structures of the Life-World, compondo a segunda e complementar parte de sua teoria, pretende a solução de problemas considerados não resolvidos após a Estruturação Significante. Schütz aqui não utiliza a construção, implicando escolhas voluntárias, mas building-up (um construir), enfatizando que o processo segue um conjunto de certas regras. $O$ pensar não é igualado à construção, mas segundo Schütz ele envolve construtos, o que elucida seu caráter instrumental e enfatiza que há sempre um sujeito em ação que leva a cabo essas interpretações e escolhas, selecionadas de um contexto universal pela atividade de nossas mentes.

Com relação a esses primeiros construtos do senso comum na vida cotidiana (1967, p.10), devemos notar que o mundo no qual ocorrem não é um mundo privado, mas, desde o início, um mundo intersubjetivo da cultura, no qual vivemos como humanos entre humanos. E é mesmo um mundo da cultura, na medida em que o mundo do cotidiano é um universo de significância, uma conexão de sentido que temos que interpretar a fim de encontrar nosso caminho dentro dele e lidar com ele de forma bem sucedida (1967, p.10). Essa conexão de sentido (que distingue o reino da cultura do reino da natureza) se origina e foi instituída por ações humanas e, destarte, aponta de volta para o sentido subjetivo originalmente atado a ela, tal como desenvolvido pelo sujeito em ação. Esse sujeito pode ser nós mesmos, um outro ser humano ou então vários que sejam contemporâneos ou predecessores.

Todos os objetos culturais - ferramentas, simbolos, sistemas de linguagem, obras de arte, instituições sociais, etc. apontam de volta para sua origem e significado das atividades de sujeitos humanos. (1967, p.10; ver também 1974, p.191)

Todos os fenômenos do mundo social implicam, em seu sentido, um núcleo especificado de significação que um sujeito em ação 
empresta a seus atos. Inteligível, portanto, é apenas a ação do indivíduó singular e isso especificamente implica significar (1974, p.13). Assim, o sentido subjetivo que o ator desenvolveu durante a produção de objetos culturais (não naturais) cunha os fenômenos do mundo social..

$\mathrm{O}$ arcabouço teórico de Schütz tem sido considerado como egológico (Srubar, em Schütz 1981, p.55), o que significa que ele deve ser entendido através do papel central do sujeito e da subjetividade. Introduzindo o ego e o alter-ego como dois termos básicos da sociabilidade (ver também Hanke 2003a), a questão do sentido subjetivo do alter-ego é respondida pela análise das capacidades da consciência do ego. A transferência do ego para o alter-ego e a camada de intersubjetividade são atingidas pela The General Thesis of the Alter Ego [A Tese Geral do A]ter-Ego] (Schütz 1974, pp.137139,1967 , pp.172-175), que considera as estruturas do ego e do alter-ego como iguais em seus fundamentos estruturais mas diferentes em conteúdo. Por exemplo, um sujeito tem uma sensação subjetiva de tempo que ele experimenta. É diferente de um outro, mas o sujeito também supõe que este outro tenha uma sensação temporal qualquer, durée ou tempo interior. Schütz e Aron Gurwitsch tiveram um debate sobre se é o ego ou o alter-ego o marcador do ponto de partida no mundo da vida. A ênfase de Gurwitsch foi no segundo, a de Schütz no primeiro.

O conceito egológico da mente nos conduz a um problema que é nomeado à moda de Descartes e que foi criticado por causa disso (Tácussel 1998, p.11). (Deve-se notar que, se uma idéia é rotulada de cartesiana, isso não significa que ela deve ser encontrada em algum escrito de Descartes exatamente dessa forma. Na verdade, tanto Husserl quanto Schütz estimam Descartes, mas certamente não em uma grosseira variante cartesiana.) O ponto é uma estrita separação entre a mente humana (Bewusstsein) e o mundo externo, com a mente desenvolvendo representações desse mundo externo. Sem pretender entrar em discussões filosóficas, para o processo de comunicação é importante que tenhamos um conceito de mente de alguma forma ligada a um corpo, um modelo também conhecido como "prisão cartesiana". 
Importante é a mudança radical do conceito de mente pelo professor de Husserl, Brentano, descobrindo o caráter intencional do pensamento, e seu desenvolvimento posterior por Husserl. O fato de a cognição humana exibir intencionalidade significa que a cognição é sempre de algo. A consciência é sempre consciência de. Pode-se ver isso claramente nos atos de crer, saber, querer, desejar, lembrar, esperar, imaginar, e assim por diante. Por exemplo, um ato de crença é sempre dirigido para um objeto ou estado de coisas particular, mesmo se essa direção é indeterminada em alguns aspectos. Não seria possível imaginar uma crença que não seja sobre algo em particular.

A realização da intencionalidade rompe as barras da prisão cartesiana que dividem o interno do externo: como os atos são considerados como dirigidos para algo, a constituição desses "algos" é vista como uma realização de nossa consciência, e não como realidade que existe independentemente de nossa concepção dela.

Ora, a abertura através da intencionalidade se limita à rełação entre a consciência e seus objetos e já foi criticada por isso (por exemplo, por Habermas em termos de bewusstseinsphänomenologische Begrenzung, limitação da noçăo fenomenológica de consciência), e o que não vemos aqui é a acentuação dos processos comunicativos e interativos. Essa necessidade é também sentida por Schütz após analisar a constituição do sentido pelo ego (com as teorias de Husserl e Bergson), quando ele se volta para o domínio do mundo social (1974, p.137). Este é exatamente o ponto em que uma teoria dos signos é desenvolvida e incorporada à sua teoria.

A intersubjetividade é, de acordo com Schütz (em crítica a Husserl a essa altura), a categoria ontológica fundamental da existência humana no mundo (1966, p.82) e um dado (Gegebenheit) do mundo da vida. Como esse caráter social é essencial para o mundo da vida e não é uma camada acrescentada, a intersubjetividade e a comunicação fazem parte dos planos e ações dos sujeitos individuais (Gurwitsch, in Schütz 1971 a: XXIX, Schütz/Luckmann 1984: 316, 317). E sua Teoria do Entendimento do Outro (Theorie des Fremdverstehens) com relação ao mundo da vida e o estabelecimento 
e interpretação de atos da vida cotidiana (1974, p.26) também cobre o estabelecimento e a interpretação dos sentidos de signos e produtos (1974, p.203-204). Assim Schütz estima uma teoria dos signos: o modo como superar transcendências (superar outros 'mundos', como a religião, sonhos, artes, etc.) é mostrado por uma teoria dos sistemas apresentativos; e, por meio dos signos, a intersubjetividade é estabelecida e nossa experiência imediata é superada e transcendida. Por signos e símbolos são medidas essas partes do mundo da vida que não são parte do mundo cotidiano partilhado em comum. Isso leva ao Structures of the Life-World como a parte complementar da teoria de Schütz e a transição de um sujeito único para o mundo social. E esse é o ponto em que os signos e a comunicação têm a sua entrada. A fim de se comunicar, o ser humano deve usar certos instrumentos que não são encontráveis na natureza, mas que têm que ser produzidos, num movimento de estabelecimento de signos, e que os outros têm que reproduzir, num movimento de interpretação, todos esses instrumentos sendo subsumidos sob o conceito de signo, do qual a linguagem é o sistema mais importante. (Schütz/Luckmann 1979, p.141).

\section{Semiótica}

\subsection{Signos e apresentação}

A concepção triádica de signo de Schütz é amplamente difundida em semiótica (ver por exemplo Eco 1977, p.30; Gordon 1990; Kraus 1990). Um desses três elementos é o intérprete (Subjekt, sujeito) do signo (Schütz/Luckmann 1984, p.305), que é considerado como possuidor de intençôes comunicativas desde o início. Assim, complementar a um ego cogitans que estabelece os signos, existe também um ego cogitans que interpreta os signos (Schütz 1974, p.168). Este aspecto do destinatário do ato comunicativo é considerado em toda a sua argumentação. Entre o signo e o que é significado, portanto, existe uma relação de representação que é instalada pelo intérprete através de um ato de interpretação construtiva (Schütz 1974:30, referindo-se a Husserl 1928 II, p.25). 
Schütz introduz, em um estilo fenomenológico, dois termos: algo "significante" e algo por ele "significado", ambos, em conjunto, formando o signo. Esse, distinguindo entre designans e designatum, corresponde ao uso normal em lógica e filosofia (e também ao conceito de aliquid stat pro aliquo usado desde Santo Agostinho para desenvolver vários dos conceitos de signo subsequentes). No uso do signo exige-se uma síntese entre aquilo que está presente ("significante") e aquilo que não está presente ("significado"), uma síntese que é chamada de apresentação.

Como não temos acesso direto a outras mentes (Bewusstsein), todo o nosso conhecimento de outras mentes se baseia em referências apresentacionais $(1967$, p.313). E como o mundo da vida cotidiana é, desde o início, intersubjetivo, o uso dos signos é fundamental para o mundo intersubjetivo. Cada entendimento de um outro "alguém" (Fremdseelisch, que significa, literalmente, algo como outras almas) carece de um objeto do mundo externo, que é tomado como uma referência apresentacional daquilo que Aristóteles chama de pathemata (movimentos da alma). Schütz cita Aristóteles nessa ocasião, revelando sua tradição ocidental em semiótica.

Precisamente, em cada situação apresentacional (1967, p.299; 1971a, p.345), há quatro ordens envolvidas:

a) O esquema aperceptual, a ordem de objetos à qual o objeto imediatamente percebido pertence se experimentado como um em-si, desconsiderando quaisquer referências apresentacionais (o "material" do signo). Por exemplo, encontrar um galho quebrado numa trilha e tomá-lo por um galho quebrado e nada mais. Em outras palavras, percebe-se um objeto, desconsiderando referências apresentacionais (se é que elas existem), mas algo é percebido.

b) O esquema apresentacional, a ordem de objetos aos quais o objeto imediatamente percebido pertence se tomado não em si mesmo mas como membro de um par apresentacional, isto é, referindo-se a algo que não é ele mesmo (um "signo", incluindo algo significado). O galho quebrado é tomado não como apenas um galho quebrado, mas como membro de um par apresentacional. $O$ que é apresentado seria, digamos, um aviso como Canibais 
perigosos à frente!. O galho quebrado àlém de objeto percebido 'é parte de um par, o outro membro do par sendo o aviso.

c) O esquema referencial, a ordem de objetos à qual pertence o membro apresentado de um par que é percebido de maneira meramente analógica. Esses objetos nó lugar dos quais está o signo são, eles mesmos, estruturados, de modo a termos uma "ordem dos objetos". A ordem dos objetos à qual pertence o membro apresentado do par, neste exemplo, é "o mundo do canibalismo e seus habitantes". Nada é dito sobre o estatuto ontológico desse esquema referencial, de modo quie o ego que estabelece o signo, neste exemplo, o galho quebrado, e o intérprete que se depara com ele podem ambos acreditar na existência dos canibais ou não. A utilidade da diferença entre o estabelecedor do signo e o intérprete do signo é também demonstrada ao se mostrar as intençôes e as interpretações diferentes dos usuários de signos. Suponha que o colocador do galhọ quebrado pretende avisar "perigosa cachoeira à frente vire à direita", e o que o encontra interpreta-o como o aviso sobre os canibais. Ele ainda pode virar à direita e se salvar. Ele tomará o signo comó prova e como razão de continuar acreditando na existência dos canibais porque, afinal, ele conseguiu se safar deles. O mesmo vale para o colocador do signo, quando observa o "antropofagófobo" tomar a direita. Portanto, vemos aqui:

1. um princípio pragmático, o de acreditar como verdadeiro aquilo que é útil para nós.

2. que as intençōes de um falante e as de um ouvinte envolvidos em comunicação podem se distanciar sem que qualquer um dos participantes se dê conta disso.

d) Finalmente, o esquema contextual ou interpretacional, o tipo particular de emparelhamento ou contexto pelo qual o membro apresentante é ligado ao membro apresentado, ou a relação que prevalece entre o esquema apresentacional e o referencial. Uma linguagem ou código de escoteiros é um exemplo de um esquema interpretacional ou contextual. Quando o termo man eater é traduzido do inglês para o português "canibal" ou "antrơpófago", 
este esquema se altera, i.e., altera o tipo de emparelhamento entre membro apresentacional e o apresentado.

Em geral, todos os quatro esquemas (schemata) fazem parte de cada processo sígnico. Que eles são necessários pode ser demonstrado da seguinte forma. Imaginemos um sujeito que não fale português. Alguém fala a palavra "canibal". Ele ouve a palavra muito bem, de forma que o esquema aperceptual está completo. Ele também pode entender que não é um mero som, mas uma palavra significativa em um idioma (poderia até talvez dizer, por várias razões, que idioma seria), de maneira que o esquema apresentacional não está vazio. Supondo também que ele sabe tudo sobre canibais, porque já leu todos os livros sobre eles, ou seja, ele tem seu esquema referencial completo. Mesmo assim, sem o esquema interpretacional do português, o signo não é totalmente inteligível. Outras combinações podem se formar, por exemplo, não sabendo nada sobre a cultura dos antropófagos, que, neste exemplo, seria a ordem dos objetos, seu conhecimento de idiomas não seria suficiente para entender o signo.

Embora todos esses esquemas sejam parte do processo sígnico, um deles pode ser escolhido como sistema de referência e os outros sistemas podem ser considerados a partir dessa perspectiva. Podemos falar sobre diferentes termos para designar os mesmos objetos em línguas diferentes, assim discutindo molduras contextuais. Se não entendemos alguém ao telefone e pedimos que fale mais alto, estamos falando da incompletude do esquema aperceptual. Posso tentar convencer as pessoas a votarem em mim para presidente em uma campanha política, sendo a única pessoa capaz de salvá-las dos antropófagos, dando, assim, um novo conteúdo ao esquema apresentacional ("simbolização"). E, é claro, podemos discutir a ordem dos objetos, a (não-)existência dos canibais, sua história etc. Ora, os signos são sempre, como se bem sabe, usados em um contexto, o que Schütz chama de Sinnzusammenhang, um composto de "ligação" ou "conexão" (Zusammenhang) e "sentido" (Sinn). No contexto do idioma inglês, Schütz usa a expressão meaning-context, mas estou convencido de que isso signifique mais precisamente algo que pode ser chamado de "conexão de sentido" ou "juntidade do 
sentido". A noção de contexto é apenas uma das formas dessa conexão.

Primeiro, as experiências que são significadas elas mesmas ficam em uma "conexão de sentido". Há uma referência a "objetos e circunstâncias", formulada por Bühler (ver Hanke, 1999).

\subsection{Signo, sistema signico e significado objetivo}

Em segundo lugar, um signo é parte de um sistema sígnico (Schütz desenvolve isso independentemente de Saussure, mas refere-se a ele em escritos posteriores). Um sistema sígnico consiste nos significados dos signos e nos signos que transmitem e mantêm esses sentidos, é uma conexão de sentido objetiva. A aplicação de objetivações como sistemas sígnicos a intenções subjetivas é sempre pré-experienciada, e nosso "já nos conhecemos" é resultado de experiências prévias, que formam um sedimento e uma parte de nossa experiência geral. Esse conhecimento de fundo é necessário para a produção de um signo, porque deve ser interpretado antes de ser estabelecido ou colocado. Antes que alguém interprete algo que disse, tenho que interpretá-lo eu mesmo a fim de poder dizê-lo. Cada uso de signos refere-se a uma pré-experiência e a um uso passado, de forma que aquele ato singular faz parte de uma série interminável de semiose (ver Peirce, e.g. 1986, p.424).

\subsection{Pragmática: a integração situacional e subjetiva do sentido}

Em terceiro lugar, estabelecer um signo exige uma șituação concreta, que é uma conexão de sentido situacional. Essa conexão de sentido situacional pode ser suficiente para entender o significado de um signo, por exemplo, quando alguém entra em uma sala e diz algo em um idioma estrangeiro que é um tipo de saudação, tendo como base o comportamento dos sujeitos, podemos inferir que se trata de um cumprimento, ou seja, é possivel inferir o significado a partir da situação.

O intérprete do signo e destinatário da comunicação também faz parte da conexão de sentido situacional. Em geral, o 
comportamento comunicativo está sintonizado com a situação e o destinatário. Em análise de conversação e em etnometodologia, isso ficou depois conhecido como recipient design (Sacks et al. 1974:727). Falando sobre um evento qualquer, o relato dado vai diferir em relação à pessoa; contamos a mesma coisa de maneiras diferentes para um pai, um amigo, um colega, etc.

Um signo se liga a um sentido objetivo quando a pessoa que produz o signo e a que o interpreta tomam o sentido de acordo com algum sistema sígnico pré-experienciado como por exemplo o código que liga galhos quebrados a canibais. Esse sentido estabelecido e fixo é invariante em todas as experiências presentes, que têm o rótulo de aqui, agora, e assim. Mas, além do sentido objetivo, todas as expressões também têm um sentido subjetivo ou ocasional, resultante de elementos específicos de uma situação, tais como a especialidade de uma pessoa, a hora, e o contexto da conversa. Apesar de haver dicionários com significados constantemente iguais e objetivos, as pessoas se envolvem o tempo todo em conversas em que nem tudo se iguala. Também, nossas biografias são necessariamente diferentes e desenvolvem o conhecimento prévio de que nos utilizamos para as interpretações subjetivas.

Toda a produção e a interpretação de signos exige tomar o sentido subjetivo e ocasional necessário para a referência sobre essa pessoa específica em nosso conhecimento, seus hábitos de interpretação, expressão, e modos de modificações de atenção, além da motivação de fazê-la comunicar-se.

Como toda experiência que temos se liga a suas circunstâncias específicas de ocorrência, assim também a integração ocasional do próprio sentido. E o grau de profundidade em que queremos penetrar no processo interpretativo é uma questão pragmática, no sentido de que segue o interesse fornecido por nosso sistema de relevância. Qual camada da conexão de sentido é levada em consideração vai depender daquilo que é considerado relevante (uma teoria da relevância, o desenvolvimento posterior de seu livro The Problem of Relevance, é parte importante do Structures of the Life-World I). $O$ entendimento, que é a interpretação da apresentação de um signo envolve, portanto, três aspectos: 
a) o signo e sua relação com um sistema de signos;

b) o sentido subjetivo, a interição de quem está apresentando/produzindo o signo;

c) o uso agora, aqui, neste contexto, a dimensão "ocasional" ou "contextual".

Em resumo, o arcabouçó teórico de Schutz dá ênfase à importância do sujeito, tomado aqui como a instância que desenvolve o sentido. Ele, pờtanto, não é um estruturalista, que atribui significado a "sistemas de signos". Como a interpretação (de signos) tem um papel central em sua concepção, ele pode se situar na tradição hermenêtutica. A base antropológica para o indivíduo é a intersubjetividade, ou seja, a comunicação e seus inistrumèntos: os signos. A comunicação é vista como um processo de apresentar signos e interpretá-los. No procésso de comunicação, a fala e os sistemas de signos (como a língua), não são isolados, mas são tratados èm conjunto. $O$ uso de signos é visto como um tipo de ato social, implicando intenções, que orientam planos de ação.

Começando a partir da situação central da comunicação face-a-face, sua teoria dos signos estende-se a todas as regiões do Mundo da Vida, nas quais ocorrem processos de interpretação de ações prévias. Assim, encontramos uma integração de teoria de comunicação interpessoal e midiática. Ele enfatiza o cáráter construtivo da cognição e da interpretaçãó e; como resultado da abordagem subjetiva, a multiperspectividade da cógnição, que, novamente, pode explicar as diferenças fundamentais de pontos de vista e de opiniões encontráveis na realidade social. E, por fim, explica a complexidade da comunicação, resultante de diferentes sistemas de relevância para a interpretação, que por sua vez geram perspectivas diferentes de cognição, o distanciamento das motivações pretendidas ao se apresentar um signo e as diferentes interpretações que daí surgem. 


\section{Bibliografia}

BERGER, P. e LUCKMANN, T. 1966. The Social Construction of Reality. A Treatise in the Sociology of Knowledge. New York: Doubleday, Garden City. [Alemão: (1969) Die gesellschaftliche Konstruktion der Wirklichkeit. Eine Theorie der Wissenssoziologie. Frankfurt/Main: Fischer. Portugûes: (1998, 15 ed.) A Construção Social da Realidade. Tratado de Sociologia do Conhecimento. Petrópolis: Editora Vozes].

CAPALBO, C. 1998. Metodologia das Ciências Sociais. A Fenomenologia de Alfred Schutz. Londrina: Editora UEL.

$\mathrm{ECO}, \mathrm{U} .1977$. Zeichen. Einführung in einen Begriff und seine Geschichte. Frankfurt/Main: Suhrkamp.

GOODMAN, N. 1978. Ways of Worldmaking. Indianapolis: Hackett.

GORDON, T. W. 1990. C. K. O. Edward Sapir, Leonard Bloomfield, and the Geometry of Semantics. In: NIEDEREHE, H.-J.; KOERNER, K. (org.). History and Historiography of Linguistics, vol. II (Studies in the History of Language Sciences, 51), Amsterdam, pp. 812-832.

GRATHOFF, R. 1989. Milieu und Lebenswelt. Einführung in die phänomenologische Soziologie und die sozialphänomenologische Forschung. Frankfurt/Main: Suhrkamp.

HANKE, M. 1999. Expressão, representação e apelo. $\mathrm{O}$ modelo Organon da linguagem de Karl Bühler. In: Geraes. Revista de Comunicação Social 50, pp. 26-33.

2002. Alfred Schütz. Wien: Passagen.

2003a. A Noção de Sociabilidade: Origens e Atualidade. In: França, Vera/Weber, Maria Helena/ Paiva, Raquel e Sovik, Liv (Orgs.): Estudos de Comunicação. XI. Compós. Porto Alegre (Sulina) 127-142.

2003b, org. Themenschwerpunkt: Zeichentheorie bei Alfred Schütz. Kodikas/Code 26.

. 2003c. Zeichensetzung und Zeichendeutung. Zur sozialphänomenologischen Semiotik von Alfred Schütz. In: Kodikas/Code 26, 7-23.

HUSSERL, E. 1928. Logische Untersuchungen. Vol. 2,, primeiro parte: Untersuchungen zur Phänomenologie und Theorie der Erkenntnis. Halle a.d.S.: Niemeyer. 
KRAUS, M. 1990. Platon und das semiotische Dreieck. In: Poetica 22 , pp. 242-281.

SACKS, H. SCHEGLOFF, E. JEFFERSON, G. A Simplest Systematics for the Organization of Turn-taking for Conversation. In: Language 50, 1974, pp. 696-735.

SCHÜTZ, A. 1932. Der sinnhafte Aufbau der sozialen Welt. Eine Einleitung in die verstehende Soziologie. Wien: Springer. [1974 Frankfurt/Main: Suhrkamp]

1962, 1964, 1966, 1996. Collected Papers (CP). Vol. 1: The Problem of Social Reality. Ed. Maurice NATANSON. Vol 2: Studies in Social Theory. Ed. Arved BRODERSEN. Vol. 3: Studies in Phenomenological Philosophy. Ed. Ilse SCHÜTZ. Den Haag: Martinus Nijhoff. Vol 4. Eds. Helmut WAGNER, George PSATHAS e Fred KERSTEN. Dordrecht: Kluwer.

1970. Reflections on the Problem of Relevance. Ed. Richard ZANER, Yale: University Press.

1971. Das Problem der Relevanz. Ed. Richard ZANER, introdução Thomas LUCKMANN. Frankfurt/Main: Suhrkamp.

1971. Gesammelte Aufsätze. Vol 1: Das Problem der sozialen Wirklichkeit. Vol. 2: Studien zur soziologischen Theorie. Vol 3: Studien zur phänomenologischen Phílosophie. Den Haag: Martinus Nijhoff.

1981. Theorie der Lebensformen. (Frühe Manuskripte aus der Bergson-Periode). Org. Ilja SRUBAR. Frankfurt/Main: Suhrkamp.

1979. Fenomenológia e Relações Sociais. Textos escolhidos de Alfred Schutz. Organização e introdução de Helmut R. WAGNER. Rio de Janeiro: Zahar.

2002. O Estrangeiro. Um Ensaio em Psicologia Social. In: GERAES. Estudos em Comunicação e Sociabilidade, 53, p. 5059.

SCHÜTZ, A., LUCKMANN, T. 1979. Strukturen der Lebenswelt. Vol. 1. Frankfurt/Main: Suhrkamp [tradução inglês: The Structures of the Life-World 1973, London: Northwestern University Press].

1984. Strukturen der Lebenswelt. Vol 2. Frankfurt/Main: Suhrkamp. 
PEIRCE, C. S. 1986. Semiotische Schriften. Vol. I. Org. e tradução de Christian KLOESEL e Helmut PAPE. Frankfurt/Main: Suhrkamp.

TACUSSEL, P. 1998. Comunidade e sociedade: a partilha intersubjetiva do sentido. In: Geraes. Revista de Comunicação Social 49, pp. 3-12.

TEIXEIRA, C. C. 2000, org. Em Busca da Experiência Mundana e seus significados. Georg Simmel, Alfred Schutz e a Antropologia. Rio de Janeiro: Relume Dumará. 